\title{
Analysis of Technology Effectiveness of Lean Manufacturing Using System Dynamics
}

\section{Hasan Hosseini-Nasab, Mohammad Dehghani, and Amin Hosseini-Nasab}

School of Engineering, Yazd University, P.O. Box 89195-741, Yazd, Iran

Correspondence should be addressed to Hasan Hosseini-Nasab; hhn@yazd.ac.ir

Received 30 June 2013; Accepted 29 August 2013

Academic Editors: C. A. Bulucea and T. F. Espino-Rodriguez

Copyright (c) 2013 Hasan Hosseini-Nasab et al. This is an open access article distributed under the Creative Commons Attribution License, which permits unrestricted use, distribution, and reproduction in any medium, provided the original work is properly cited.

In today's competitive environment, organizations are seeking to improve their position in the market. Lean manufacturing is an effective tool for elevating the competitiveness of organizations based on the fact that each can find its own way of improvement. Technology improvement is considered to be one of lean manufacturing's dimensions. Technology is defined as the usage and knowledge of tools, techniques, crafts, systems, or methods of organization, with the aim of solving a problem or creating an artistic perspective. A dynamic model could be appropriate for analyzing the interrelated behavior of technology and lean manufacturing. Despite the fact that there are plenty of papers and case studies on the applications of Lean manufacturing in organizations, only a few are focused on the dynamic aspects of the system. In this paper, a dynamic model is presented in which Lean manufacturing is linked with technology by causal relationships. The notable advantage of the presented model is the ability to alter a parameter to find how it affects others parameters by considering key results. Thus, it is reasonable to expect that the results of such analysis could somewhat improve the efficiency of technology improvement on Lean manufacturing.

\section{Introduction}

Lean philosophy has been prevalent in the manufacturing industry during recent decades. However, even today, a large number of manufacturers are struggling to successfully embrace Lean principles. Results of the Aberdeen Group's report on lean scheduling indicate that, among manufacturers, those who adopted Lean software applications have exceeded many of their competitors, thus making Lean software adoption vital for manufacturers. What manufacturers require is to standardize Lean processes across their enterprise by establishing a Lean center and providing factory floor data as actionable intelligence, in order to successfully leverage their investments in technology [1].

In today's competitive world with its vast and rapid changes in scientific-technical areas and continuous challenges in economical-social systems, there are still many firms with a suitable position. These firms are flexible, pure, and customer oriented due to proper use of available facilities, suitable utilization of new sources for producing goods, and introduction of desirable services with suitable quality. Using philosophies like Lean manufacturing and employing tools such as technology, firms can establish an efficient and stable system to improve their weak points and protect their strong points (recoverable areas), enabling them to continuously identify their planning priorities and recover their recoverable areas by using corrective actions, resulting in gradually passing organizational transcendence levels and improving their efficiency.

Among various tools for performing Lean manufacturing assessments, technology has remarkably allowed the obtaining of world class function as well as recovering job function. In addition, technologies have stimulated immense attention as they provide a powerful tool for continuous recovering which is the focus of many organizations and firms. The general aim of technology is the reorganization of tools, techniques, crafts, systems, and methods of organization together with the method of applying them to solve a problem or create an artistic perspective. In order to reach this goal, interactions should be used to identify the cause and effect of relationships between technology and Lean manufacturing. In this way, the main problem of an organization originates from little or weak identification of the cause and effect structure between 
technology and Lean manufacturing, while a systemic approach can solve this issue. The relationship observation from systemic sight is in consistence with primary assumptions of its development. Systemic approach suggests that all different aspects and organizational areas are related to each other, and one cannot recover an area without affecting other areas even in a whole-area recovery. On the other hand, among several observable variables and their relations, special cause and effect loops are prevailing in determining the general behavior of a system.

Challenges from global competitors during the past two decades have prompted many manufacturing firms to adopt new manufacturing approaches [2-4]. In particular prominent among these is lean manufacturing $[5,6]$. With the notable exception of [7], there is relatively few published evidence about the implementation of lean practices and its effective factors. A majority of articles on the topic of lean manufacturing systems focus on the relationship between implementation of lean and technology.

However, conceptual research continues to stress the importance of the effect of technology on lean manufacturing programs. We specifically examine the relationship between the factor of technology and lean systems. This contextual factor has been suggested as a possible facility to implement lean manufacturing systems.

\section{Theoretical Bases}

2.1. Lean Manufacturing. Lean manufacturing or Lean production, often simply, "Lean," is a production practice that considers the expenditure of resources for any goal rather than the creation of value for the end customer, which is considered wasteful and a target for change. Working from the customer's perspective who consumes a product or service, "value" is defined as any action or process that he would be willing to pay for. Basically, lean is centered on preserving the value, with less work. Lean manufacturing is a generic process management philosophy derived mostly from the Toyota Production System (TPS) (hence, the term Toyotism is also prevalent) and identified as "Lean" only in the 1990s $[6,8,9]$. The original Toyota seven mood reduction is a well-known approach to improving overall customer value, but there are varying perspectives on how this is best achieved. The steady growth of Toyota, from a small company to the world's largest automaker, has focused attention on how this was achieved [10]. Vinodh and Balaji [11] reported a study which is carried out to assess the leanness level of a manufacturing organization in which a leanness measurement model has been designed, the leanness index has been computed, and a computerized decision support system has been developed. The model computes the fuzzy leanness index, Euclidean distance and identifies the weaker areas which need improvement.

Lean manufacturing is a variation in the theme of efficiency based on optimizing flow; it is a present-day instance of the recurring theme in human history toward increasing efficiency, decreasing waste, and using empirical methods to decide what matters, rather than uncritically accepting preexisting ideas. As such, it is a chapter in the larger narrative, that also includes such ideas as the folk wisdom of thrift, time and motion study, Taylorism, the Efficiency Movement, and Fordism. Lean manufacturing is often seen as a more refined version of earlier efficiency efforts, building upon the work of earlier leaders such as Taylor and Ford and learning from their mistakes [12]. Leanness assessment using multigrade fuzzy approach was proposed by Vinodh and Suresh [13]. In the research, a leanness measurement model incorporated with multigrade fuzzy approach was designed. This is followed by the substitution of the data gathered from a manufacturing organization. After the computation of leanness index, the areas for leanness improvement have been identified. They indicated that the approach contributed in the project could be used as a test kit for periodically evaluating an organization's leanness. The performance of a lean cell that implements lean goals under uncertainty was investigated by Deif [14]. The investigation is based on a system dynamics approach to model a dynamic lean cell. Backlog is used as a performance metric that reflects the cell's responsiveness. The cell performance is compared under certain and uncertain external (demand) and internal (machine availability) conditions. He explores the effect of the delay associated with the proposed capacity policies and how they affect the lean cell performance. A model for measuring adherence to lean practices for automotive part suppliers and to assess the relationship between the firm performance and the adoption of lean principles was proposed by Sezen [15]. Their model applied to a large number of automotive part suppliers in Turkey and data was collected from 207 automotive part suppliers by using the computer-aided telephone interview method. Validity and reliability tests of the developed model of leanness are realized through exploratory and confirmatory factor analyses. The study shows that, in general, Turkish automotive part suppliers are performing their internal production in compliance with the lean manufacturing principles. Furthermore, they found that there is a significant relationship between adaptation of lean principles by the supplier firms and their performance.

2.2. Technology. Technology is the usage and knowledge of tools, techniques, crafts, systems, or methods of organization in order to solve a problem or create an artistic perspective. Technologies significantly affect the human's (as well as other animal species') ability to control and adapt to their natural environments. Human use of technology began with the conversion of natural resources into simple tools. The prehistoric discovery of the ability to control fire increased the available sources of food and the invention of the wheel helped humans in travelling and the control of their environment. Recent technological developments, including the printing press, the telephone, and the Internet, have reduced physical barriers to communication and allowed humans to interact freely on a global scale. However, not all technology has been used for peaceful purposes; the development of weapons of everincreasing destructive power has progressed throughout history, from clubs to nuclear weapons.

Technology has affected society and its surroundings in a number of ways. In many societies, technology has helped 
the development of more advanced economies (including today's global economy) and has allowed the rise of a leisure class. Many technological processes produce unwanted byproducts, known as pollution, and deplete natural resources to the detriment of the Earth and its environment. Various implementations of technology influence the values of a society, and new technology often raises new ethical questions. Examples include the rise of the notion of efficiency in terms of human productivity, a term originally applied only to machines, and the challenge of traditional norms [16].

2.3. System Dynamics. System dynamics is an approach to understanding the behavior of complex systems over time. It deals with internal feedback loops and time delays that affect the behavior of the entire system. What makes the use of system dynamics differ from other study methods of complex systems is the use of cause and effect diagrams and feedback loops in addition to the stock and flow diagram. These elements help one to argue how seemingly simple systems display baffling nonlinearity.

The field of system dynamics was developed in the early 1960 s, initially from the work of Jay Forrester at MIT. Causal loops capture mental models and relationships in a system.

Dynamic systems modeling in educational system was proposed by Groff [17]. He mentioned that applying this tool to educational policy analysis offers insights into the hidden dynamics of the current system and can be an invaluable tool in designing future scenarios. He explored underlying dynamics of the current US educational system using system dynamics modeling and offered an analysis of this tool and its practical application in the US educational system through a case study on the US state of Rhode Island in the 2007-2008 school year.

The scenario technique is a strategic planning method that aims to describe and analyze potential developments of a considered system in the future. Its application consists of several steps, from an initial problem analysis over an influence analysis to projections of key factors and a definition of the scenarios to a final interpretation of the results. The technique itself combines qualitative and quantitative methods and is an enhancement of the standard scenario technique [18]. They used the numerical values gathered during the influence analysis and embedded them in a system dynamics framework which yields a mathematically rigorous way to achieve predictions of the system's future behavior from an initial impulse and the feedback structure of the factors.

System dynamic model approach for urban watershed sustainability study was studied by Feng [19]. He investigated the dynamic interactions between natural environment and human society to model long-term trends in environmental impact and sustainable development. The data include 21 environmental, social, and economic indicators for five counties. The data show that, within the study area, population has increased by an annual average of $6.4 \%$ with a range from $-7.9 \%$ to $20.7 \%$ over 30 years. To project the future of environmental sustainability, a system dynamic model was established. Results suggest that population will remain stable, in 2010 .
Stocks and flows describe how a system is connected to feedback loops, which create the nonlinearity that can be found so frequently in modern day problems. Computer software is used to simulate a system dynamics' model for the considered situation. In such a model, running "what if" simulations for testing certain policies can greatly aid in understanding how a system changes over time [20,21].

2.4. Cause and Effect Diagrams. Causal loop diagrams are used to capture mental models and represent interdependencies and feedback processes in a system. All dynamics arise from the interaction of only two types of feedback loops, positive and negative. Positive loops tend to reinforce or amplify the occurring events in the system, while negative loops counteract and oppose change.

2.5. Stock and Flow Diagrams. Stock and flow diagrams are a central part of the dynamic system theory. They are used to capture the stock and flow structure of systems. A stock is defined as a supply accumulated for future use, while a flow describes how the stock increases and decreases by inflows and outflows. The dynamics of the system are brought forth by examining the differences between inflows and outflows to a stock.

\section{The Steps in the Modeling of a Dynamic System}

Logical steps in the modeling of a dynamic system are as follows.

(i) Definition of problems that need to be solved and the results that need to be achieved.

(ii) Analysis of the problem with the help of cause-andeffect diagrams.

(iii) Formulation of the model structure.

(iv) Collection of information, initial values, and the basic data needed for the construction of the model from existing data and/or discussion with conductors or designers who have the knowledge and experience of the system under study. The initial values, the state values, the constant values, and the data related to the policies can also be considered among these.

(v) Investigation of model validity under certain conditions to ensure model validity.

(vi) Employment of the model in testing various policies to reach the most suitable results [20].

\section{Benefits of Analyzing Technology Effectiveness of Lean Manufacturing, Using Dynamic Systems}

There are three significant benefits for using and developing system dynamics in the relationship between technology and lean manufacturing, which may be considered as below. 
4.1. Conversion of Unidirectional to Bidirectional Causality. In using technology, most organizations consider unidirectional causal relations. The use of causal loops alone is seen as problematic and in contradiction with reality. Instead of a causal relationship, this model believes that the relationship is more of an interdependence or bidirectional causality, relying on the fact that causal relationships are seldom unidirectional in the real world.

In the proposed dynamic model the effect of new technology is considered on lean manufacturing. These effects act as bidirectional, meaning that lean manufacturing also affects technology.

4.2. Considering Time Dimension in Cause and Effect Relationships. A common problem arises from the fact that time dimension is not considered as a part of Lean manufacturing, while in some cause and effect relationships a time lag does exist between the cause and effect. This time lag is not shown by technology effectiveness (TE) of lean manufacturing since it measures the cause and effect at the same time. Simply looking at different measures simultaneously is not enough, and the linkages between them must also be understood.

In the provided dynamic model in this paper, as it is in reality, a time lag exists between new technology and lean manufacturing.

4.3. A Mechanisms for Validation. The analysis of technology effectiveness of lean manufacturing using system dynamics provides the mechanism for maintaining the relevance of defined measures. The problem for managers is usually reducing the list of possible measures to a manageable (and relevant) set rather than identifying what could be measured. Thus, the advantage of checking a few numbers may become a disadvantage if the right numbers are not selected for lean manufacturing.

Furthermore, the analysis of company strategy based on the lean manufacturing approach considers the causal relationships between performance variables only in qualitative terms. This implies that managers should rely on mental simulations and heuristics in order to quantify the results of their strategy and, hence, evaluate its efficiency and effectiveness. This task is even tougher when the company system is characterized by a high degree of complexity, nonlinear relationships among variables, and delays between causes and effects.

The validity of technology effect on causal relationships between the variables has also been questioned by system dynamics. In particular, it has been demonstrated that the hypothesized links between implementing new technology and profit may be not confirmed in reality. For instance, it has been remarked that the commonly assumed causal relationship of productivity and profit may not have any empirical evidence. On the contrary, it may be seen that the costs of policies aimed to increase productivity are higher than the related benefits, both in short and long term. For such reasons, not considering the effects of technology may lead management to mistakes.

\section{Modeling Process}

The purpose of dynamic system modeling is to establish the relation between the various variables which build the system and are used to analyze decision making policies in the realm under study. The cause-and-effect diagram is an essential tool which helps in modeling the real world in the form of feedback links. The effectiveness variables in this relation are as follows.

5.1. Cause-and-Effect Diagram Modeling. The cause-andeffect diagram of this model shows the relation between technology and lean manufacturing. The key effectiveness variables in this relation are new technology, employee productivity, innovation in processes, customer satisfaction, financial sources, complexity of industry, and lean manufacturing. Expanded cause-and-effect relations between technology and lean manufacturing can be described as follows.

(i) The relationship between new technology implementation and innovation in processes.

(ii) The relationship between new technology implementation and interaction between employees.

(iii) The relationship between new technology implementation and the cost to change technology.

(iv) The relationship between new technology implementation and lean manufacturing.

In this paper due to the expanded relations defined above, the relationships between the model's variables are used in drawing the model. More description is provided as follows.

It is a common belief among enterprises that reaching lean results, regarding customer satisfaction, employee productivity, and innovation in processes, requires effective technology, which itself begins with putting together new program needs and is expanded with the compilation of organizational changes. Therefore, organizational changes and new program needs are effective on all model variables. An organization can attain productivity regarding employees only when it elects suitable approaches in improving the interaction between employees; for this reason, technology is related to employee productivity. By achieving lean results in the field of customer satisfaction, the utilization of suitable approaches is possible in innovational processes such as design and expansion of products, delivery of products and services, and management of communication with customers. Therefore customer satisfaction is related to the process. Reaching lean results in the field of financial sources requires reaching improvement in customer satisfaction and employee productivity. Therefore, the criteria of key operation results are in relation with customer satisfaction and employee productivity.

A simplified and stylized version of the qualitative model that is the end result of the first modeling phase is shown in Figure 1. In this causal loop diagram, nine interconnected feedback loops are shown and together determine the dynamic behavior of the model. These are labeled R1 $\cdots \mathrm{R} 9$ with the " $R$ " standing for "reinforcing" or positive feedback loop and B1, B2 with the "B" standing for "balancing" or negative feedback loop. 


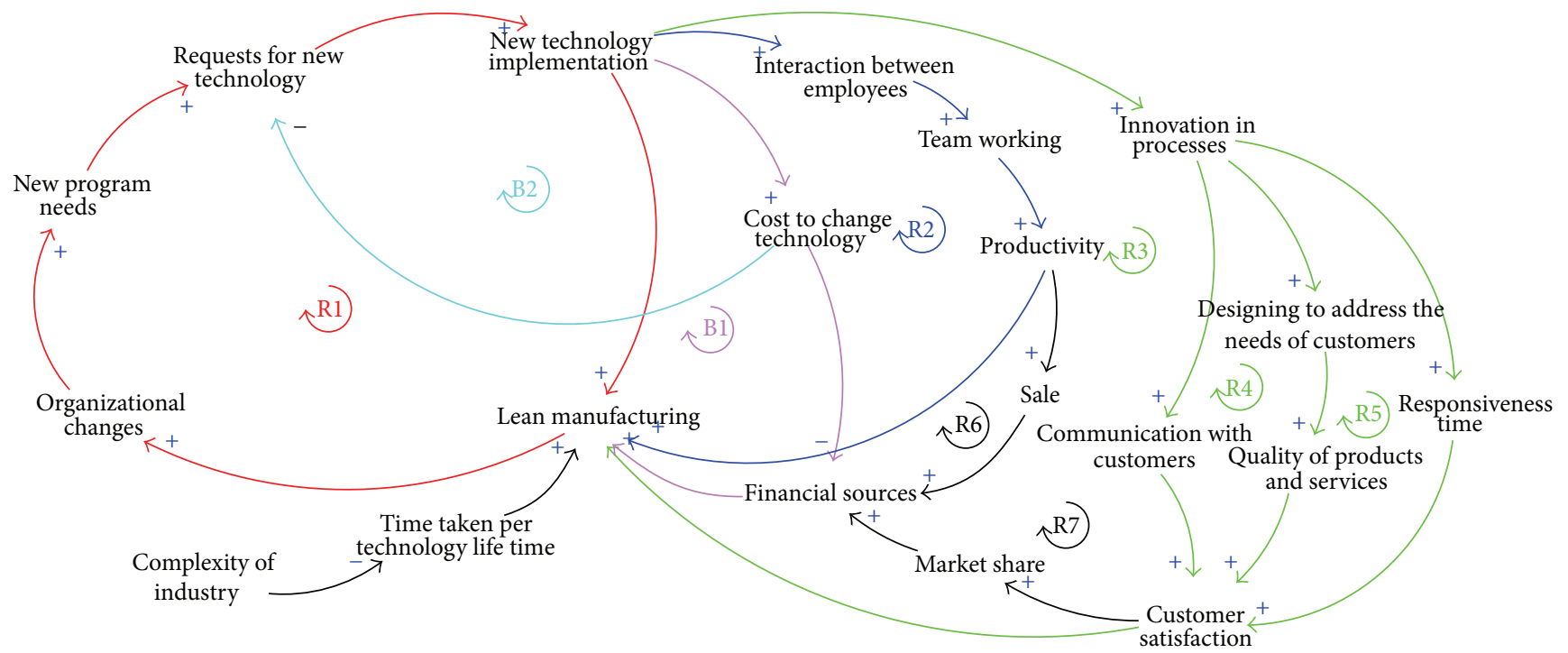

FIGURE 1: Cause-effect diagram based on the relationship between technology and lean manufacturing.

Some of the relations between variables are reviewed in the past articles $[22,23]$ and the rest is based on excellence models like the EFQM model [24].

R1: The New Technology Implementation Loop. A pertinent observation in the modeling phase was that new program needs increase as a result of an increase in organizational changes. Thereafter implementing new technology is made essential, leading to an increase in the request for new technology. Finally, implementing new technology leads to better lean manufacturing. As a result, technology is a tool that can directly affect lean manufacturing.

R2: The Productivity Loop. Interaction between employees increases as a result of implementing new technology. Thereafter employee productivity increases, leading to an increase in team working. Finally, employee productivity leads to better lean manufacturing. As a result, technology is a tool that affects productivity, and therefore productivity can affect lean manufacturing.

R3: The Communication with Customers Loop. Improvement and innovation in processes increase as a result of implementing new technology. Thereafter customer satisfaction increases, leading to better communication with customers. Finally, customer satisfaction leads to better lean manufacturing. As a result, technology is a tool that affects customer satisfaction, and therefore customer satisfaction can affect lean manufacturing.

R4: The Quality of Products and Services Loop. Improvement and innovation in processes increase as a result of implementing new technology. Thereafter customer satisfaction increases, leading to better quality of products and services. Finally, customer satisfaction leads to better lean manufacturing. As a result, technology is a tool that affects customer satisfaction, and therefore customer satisfaction can affect lean manufacturing.
R5: The Response Time Loop. Improvement and innovation in processes increase as a result of implementing new technology. Thereafter customer satisfaction increases, leading to better response time. Finally, customer satisfaction leads to better lean manufacturing. As a result, technology is a tool that affects customer satisfaction, and therefore customer satisfaction can affect lean manufacturing.

R6: The Productivity-Financial Sources Loop. Interaction between employees increases as a result of implementing new technology. Thereafter employee productivity increases, leading to an increase in team working. Thereafter, the number of sales increases as a result of an increase in productivity, which leads to a rise in financial sources. Finally, financial sources lead to better lean manufacturing. As a result, technology is a tool that affects productivity, and therefore productivity can affect financial sources.

R7: The Customer Satisfaction-Financial Sources Loop. Improvement and innovation in processes increase as a result of implementing new technology. Thereafter customer satisfaction increases, leading to better response time, quality of products and services and communication with customers. Thereafter, marketing shares increase as a result of an increase in customer satisfaction, which leads to a rise in financial sources. Finally, financial sources lead to better lean manufacturing. As a result, technology is a tool that affects customer satisfaction, and therefore customer satisfaction can affect financial sources.

B1: The Cost of Changing the Technology-Financial Source Loop. The cost to change technology increases as a result of new technology implementation. Thereafter financial sources decrease, leading to an increase in the cost of changing technology. Finally, a decrease in financial sources leads to a decrease in lean manufacturing. As a result, the cost to change technology is a tool that affects financial sources. 


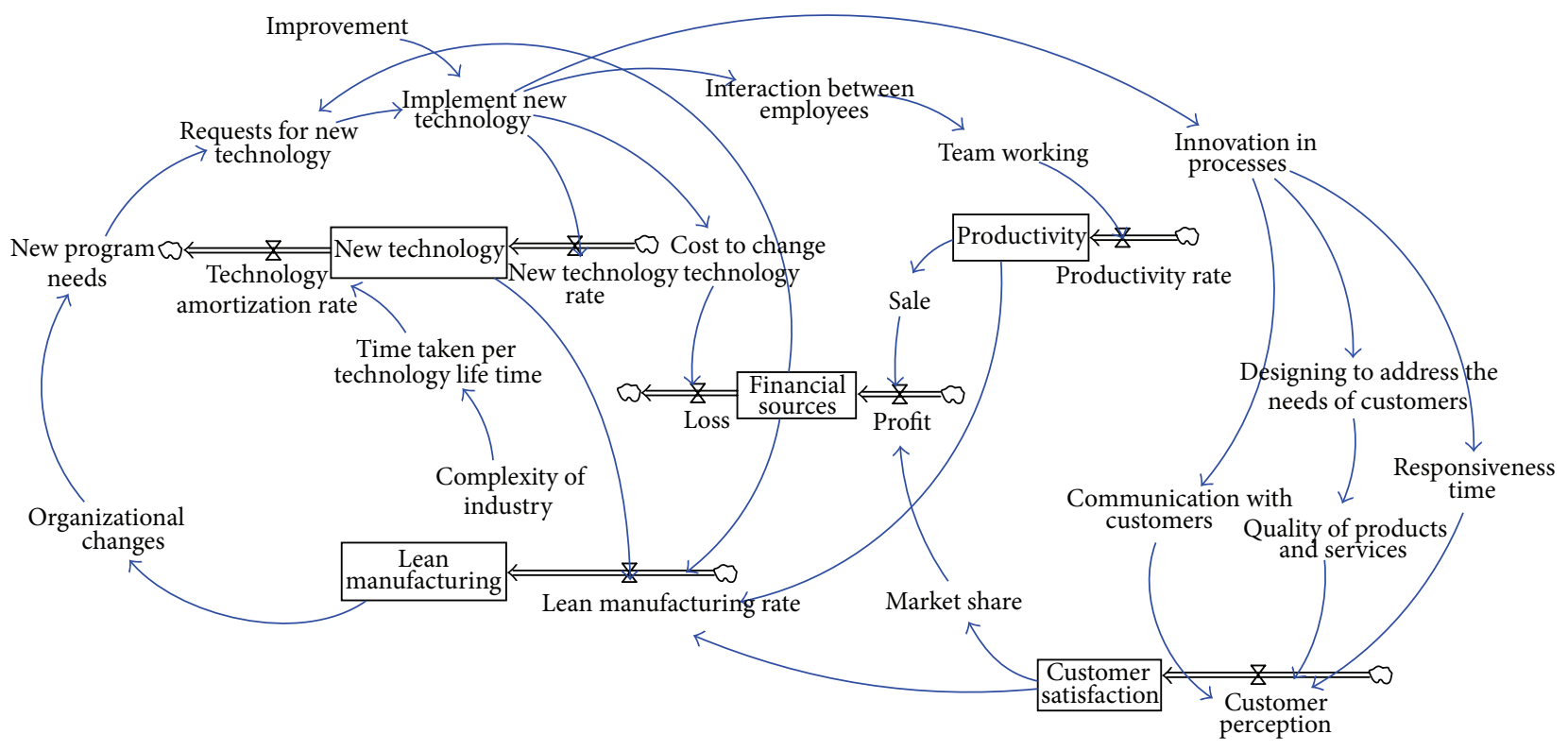

FIGURE 2: Stock and flow diagram based on the relationship between technology and lean manufacturing.

B2: The Cost to Change Technology-Requests for the New Technology Loop. Requests for new technology decrease as a result of an increase in the cost to change technology. Thereafter implementation of new technology decreases, leading to a decrease in the cost to change technology. As a result, cost is a criterion that affects requests for new technology.

Moreover, a short time pertinent observation in the modeling phase was that expenditures increase as a result of an increase in new technology, but in the long run new technology led to an increase in productivity and innovation in processes. Thereafter sale and customer satisfaction increased. Finally, sale and customer satisfaction led to better financial sources. In the short run, costs would increase, but in the long run, costs will decrease, leading to an increases in benefit. Therefore, as a result, it is necessary to consider technology in organizations' short and long time effects. In this diagram two parallel lines (II) are employed for showing delay in the relationships between variables.

5.2. Stock and Flow Diagram Modeling. In order to describe the relations between the variables and to investigate various scenarios, interviews with experts were carried out.

The stock and flow diagram based on the relationship between technology and lean manufacturing is presented in Figure 2.

The developed model is performed by using the Vensim PLE Software. Time unit is set to a year and the model is run for 13 years, starting from 2008.

To study the trend of organizational development, one can define levels during the time of new technologies' effects. In this paper, we have defined the levels as new technology, productivity, customer satisfaction, financial sources, and lean manufacturing. These levels indicate organizational changes due to the complexity of industry, during the run time.
The results of the simulation of "lean manufacturing," "financial sources," "customer satisfaction," and "productivity" levels are shown in Figure 3.

It can be seen that the behavior of Figures 3(a), 3(c), and $3(d)$ is goal seeking. This may be explained by the increase in productivity and customer satisfaction due to the new technology implementation. Consequently, lean manufacturing also improves during this time.

Furthermore, it can be seen that the behavior of Figure 3(b) in initial stages increases but shows decreasing behavior later on. In the short time, this could be explained by the rise of expenditures due to the new technology implementation, but in the long run the implemented new technology causes an increase in productivity and innovation in processes, which consequently causes a decrease in expenditures.

For the linking process between these variables, the kind of auxiliary variables in the Vensim PLE Software is set to "lookup," and is used for the relationship between the variables of the model. For example, to link between the "new program needs" variable and the criteria "organizational changes" and "new program needs," the type of the variable is set to "lookup," which shows that the trend of cause changes based on effect changes. This is expressed in Figure 4. In this diagram, "organizational changes" is placed on the $x$-axis and "new program needs" is placed on the $y$-axis.

\section{Performance Tests of the Proposed Model}

In order to validate dynamic models, conventional tests such as boundary efficiency, unit's consistency, parameter evaluation, structure evaluation, cumulative error, and the extreme value test are carried out.

(i) The boundary efficiency test suffices parameters and causal loops in the model according to the purpose. This problem is verified in the modeling phase after 


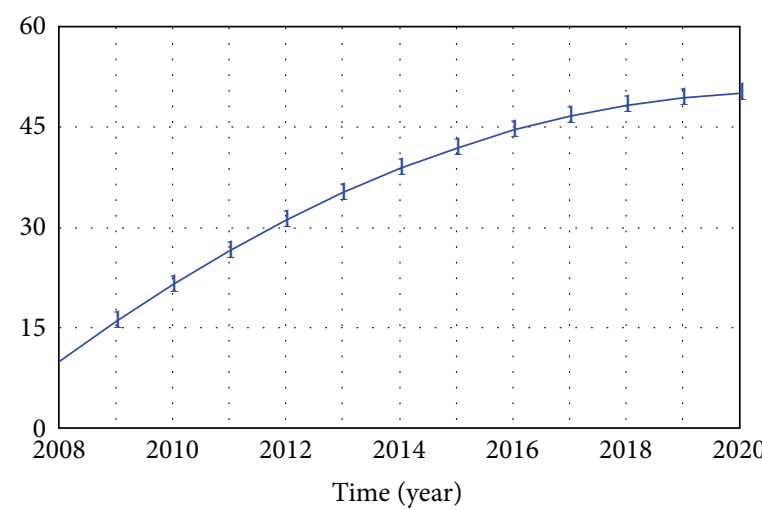

1 Lean manufacturing: current

(a) Lean manufacturing

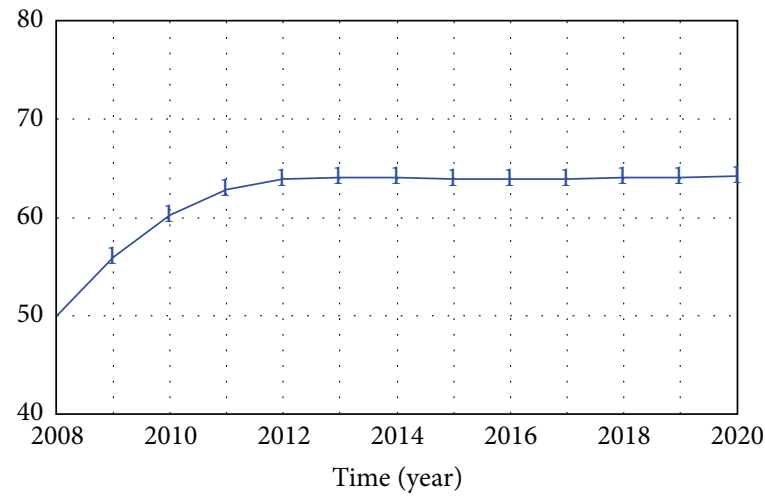

1 Customer satisfaction: current

(c) Customer satisfaction

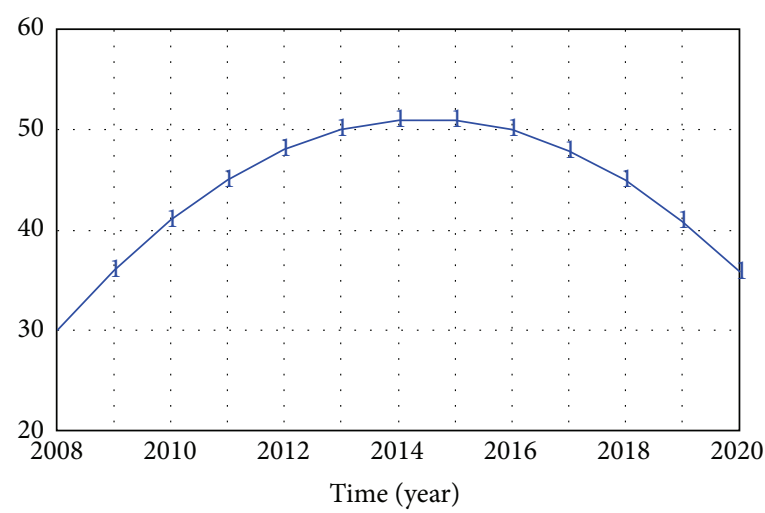

1 Financial sources: current

(b) Financial sources

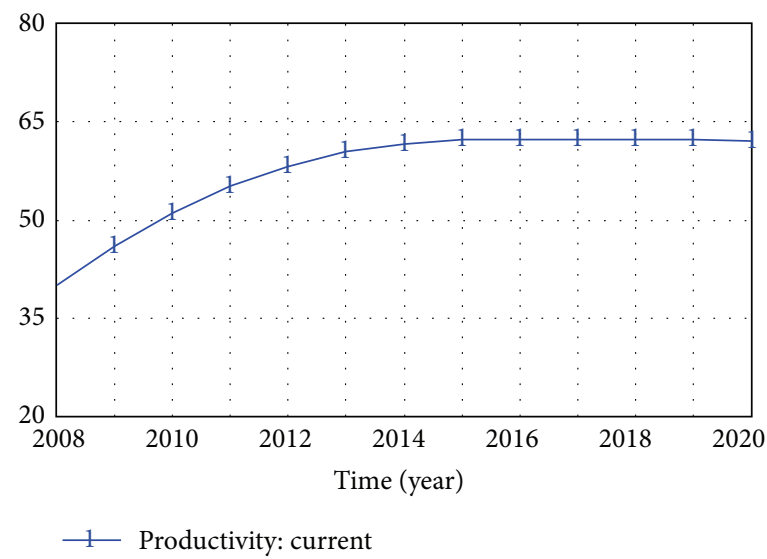

(d) Employee productivity

FIGURE 3: Behaviors of prominent variables obtained through simulation.

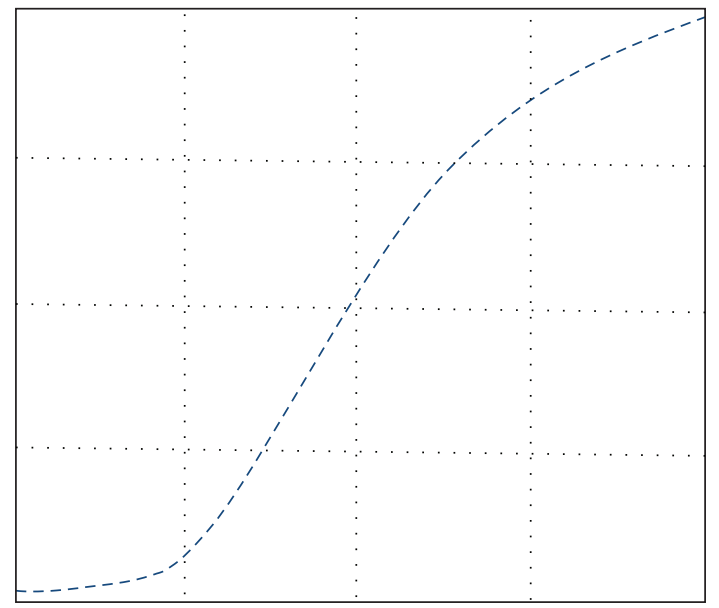

FIGURE 4: "New program needs" variable.

reaching results in the interaction with experts and has more emphasis on model logic.

(ii) The unit's consistency test emphasizes on the equality of units in the model and is verified by the software. (iii) The parameter evaluation test emphasizes on a correct definition of variable's initial amounts and on the base of objective data or anticipation. For this purpose, all used data in the simulation is taken from existing chronological data or has been adjusted on the base of anticipation.

(iv) The structure evaluation test considers the compatibility of the model behavior with its structure. This problem necessitates that variable behavior in negative and positive feedback, in the simulated model, must be orderly exponential and seeking its goal. On this base, as seen in the causal diagram, the variables from negative feedback loops and their behavior in the simulated model must be goal seeking, which can be clearly seen in Figure 5 .

(v) The cumulative error test verifies that the results of the simulation are not sensitive to the time unit. For example, if the time unit was set to one year, changing it to six months should not alter the results.

(vi) The extreme value test emphasizes on the model's resistance in limited conditions, meaning that the model must show its expected behavior under any 


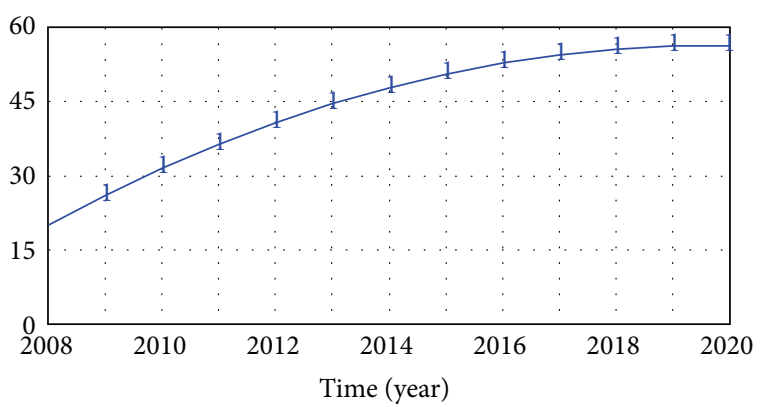

1 Market share: current

FIGURE 5: Behaviors of "marketing share" variable.

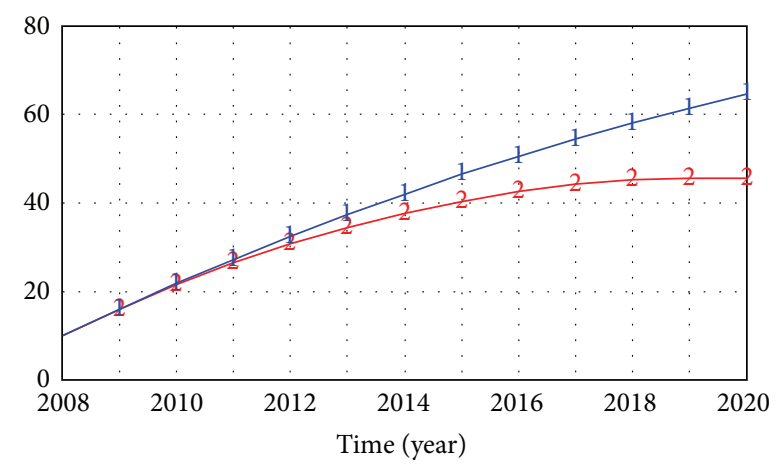

1- Lean manufacturing: 100

2 Lean manufacturing: 0

Figure 6: Behaviors of "lean manufacturing" variable.

circumstances, even under the change of policies or entry amounts. For example, even if the initial amounts of the external variables are increased or decreased greatly, the internal variables' changes must be in their genuine range. This matter is also considered in the proposed model and is verified regarding limited conditions. For example, the amount of the variable "lean manufacturing" is tested while the "complexity of industry" variable is changed from 0 to 100. The result is shown in Figure 6.

It could be seen that behavior of the "lean manufacturing" variable has not changed in its limited conditions. Consequently, by model verification, it is possible to make scenarios to analyze the results and subsequently make decisions that are discussed as follows.

\section{Policy Making}

In the proposed dynamic model an "improvement" variable is defined for the "implementing new technology" variable in order to evaluate different policies (the improvement variable is determined based on the future goals and policies of the organization). We will now discuss and compare three different policies and scenarios to find the decisions by which the firm may achieve its objectives. "Lean manufacturing" and "financial sources" are the main variables which we must pay

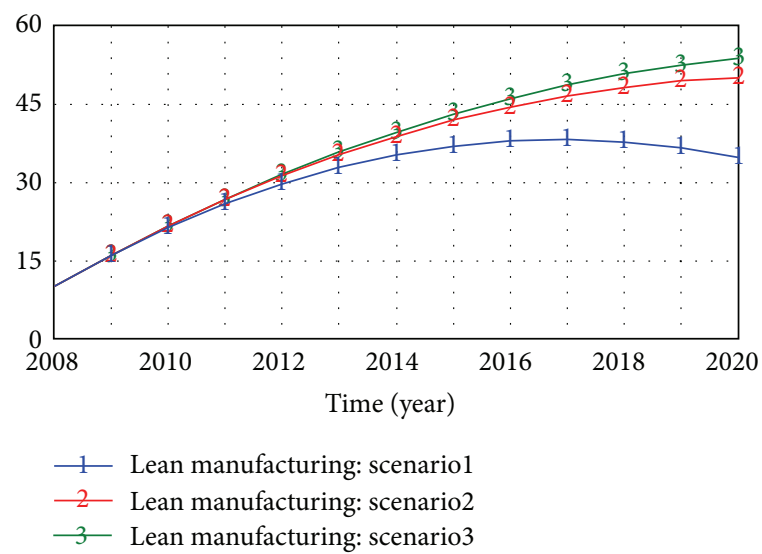

FIgURE 7: The results of applying the three policies for the "lean manufacturing" variable.

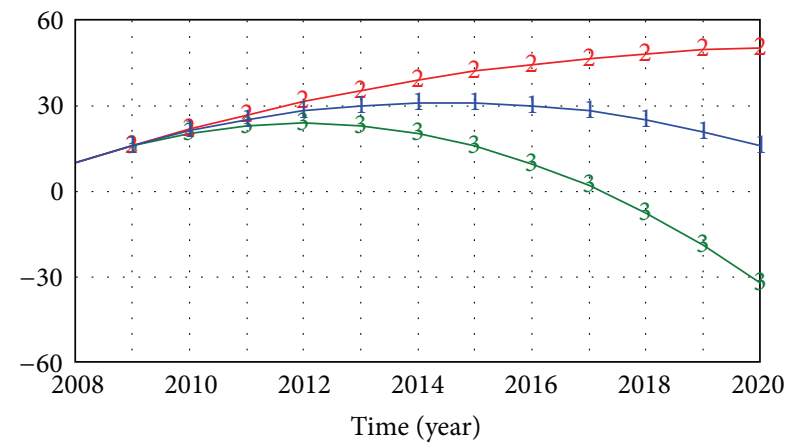

$\begin{array}{ll}1 & \text { Financial sources: scenario1 } \\ 2 & \text { Financial sources: scenario2 } \\ 3 & \text { Financial sources: scenario3 }\end{array}$

FIGURE 8: The results of applying the three policies for the "financial sources" variable.

special attention to. We will consider the following three scenarios.

Policy 1. We name the first scenario the "low improvement of technology approach." Therefore, we assume a low value of improvement in the variable, considering its logical value to be $10 \%$.

Policy 2. We name the second scenario the "middle improvement of technology approach." Therefore, we assume an average value of improvement in the variable, considering its logical value to be $25 \%$.

Policy 3. We name the third scenario the "high improvement of technology approach." Therefore, we assume a high value of improvement in the variable, considering its logical value to be $50 \%$.

The results of applying each of the above policies to the "lean manufacturing" and "financial sources" variables are shown in Figures 7 and 8.

As seen in Figures 7 and 8 the "lean manufacturing" and "financial sources" variables have a goal seeking behavior in all three scenarios. 
In Figure 7, results of the simulation show that "lean manufacturing," in all three scenarios, increases faster in the first years compared to later years and finally decreases in the end. In comparison between the three scenarios, it is observed that the third scenario has a better following of the mentioned trend than the other two scenarios.

In Figure 8, the results of the simulation show that "financial sources" in all three scenario increase at first but decrease in later years. In comparison between the three scenarios it is observed that the second scenario has a better following of the mentioned trend than the other two scenarios.

Since the trend of the second scenario in the "lean manufacturing" variable is nearly at the same level of the trend the third scenario and in the "financial sources" variable it has a better following of trend compared to the other two scenarios, hence it is considered as the best choice among the three scenarios, meaning that new technology implementation must be proportionate to its cost and income. In other words, if the improvement in lean manufacturing is lower in proportion to its increase in cost in a scenario, that scenario is declined, as is the third scenario in this paper.

Therefore, the second scenario should be chosen in enterprises, as it obtains more benefits and allows technology to be useful and valuable in lean manufacturing.

\section{Concluding Remarks}

This research provides a model with systemic function in order to analyze the relationship between technology and lean manufacturing in enterprises. The developed model is highly suitable for describing and analyzing organizations. We have introduced a new integrated dynamic approach which investigates technology effectiveness of lean manufacturing in enterprises and selects the best policy among the enforceable policies. Consequently, we have indicated the effects of powerful factors on organizational results by using the proposed dynamic model and have obtained and analyzed the trend of changes in terms of different values by utilizing the Vensim PLE Software.

Analysis of technology effectiveness of lean manufacturing, considering the dynamic behavior of the system, provides a group of advantages. The most important are as follows.

(i) Simulating the effect of important factors on enterprise results.

(ii) Performing the "what if" analysis to learn from future potential threats and scenes.

(iii) Capability of visual representation for relations between the values of the model.

(iv) Reducing the risk of performing future plans through simulating and studying the results and the conclusions of different policies.

Also, obtaining the dynamic model provides advantages for recovering evaluations, including time dimension between cause and effect. With respect to the evaluations made based on the developed model, it is indicated that the effects of change in powerful values on the results occur simultaneously. However, the effects appear during the next period rather than the same period. Therefore it is fair to say that the proposed dynamic model is a suitable tool for modeling the situation of organizations and predicting the effect of their existing strategies.

The following fields may provide a base for future research opportunities.

(i) More complete performance tests of the developed model.

(ii) Performing more simulations for different policies with different analysis of their results which would lead to a more exact conclusion.

(iii) In the developed model, we have provided the relationship between technology, employees, processes, and lean manufacturing. A future research may be to include more relations by introducing more variables, for example, the partnerships, outsources, and knowledge management variables.

(iv) Inviting experts of manufacturing systems and system dynamics for further research on the developed model may lead to the improvement of the relationships and equations of the model.

(v) Modeling and measuring alone are not enough for organizations. These techniques must be considered in social-economical systems. The developed model may be combined with organization policies to raise its efficiency. Also, discussing and developing the model by implementing it at different positions may provide guidance for future investigations.

\section{Conflict of Interests}

The authors state that they are in no way associated with or financially related to any mentioned commercial identities in this paper. Any mention of commercial identities is for illustrative purposes only and should not interfere with matters such as conflict of interests.

\section{References}

[1] Aberdeen Group, "The role of technology in lean manufacturing," August 2007.

[2] R. W. Hall, Attaining Manufacturing Excellence: Just-in-Time, Total Quality, Total People Involvement, Dow Jones-Irwin, Homewood, Ill, USA, 1987.

[3] J. R. Meredith and R. Mctavish, "Organized manufacturing for superior market performance," Long Range Planning, vol. 25, no. 6, pp. 63-71, 1992.

[4] S. Goyal and S. Grover, "A comprehensive bibliography on effectiveness measurement of manufacturing systems," International Journal of Industrial Engineering Computations, vol. 3, no. 4, pp. 587-606, 2012.

[5] J. P. Womack and D. T. Jones, Lean Thinking: Banish Waste and Create Wealth in Your Corporation, Simon \& Schuster, New York, NY, USA, 1996.

[6] J. P. Womack, D. T. Jones, and D. Roos, The Machine That Changed the World, Harper Perennial, New York, NY, USA, 1990. 
[7] R. E. White, J. N. Pearson, and J. R. Wilson, "JIT manufacturing: a survey of implementations in small and large U.S. manufacturers," Management Science, vol. 45, no. 1, pp. 1-15, 1999.

[8] A. Mahfouz, J. Shea, and A. Arisha, "Simulation based optimization model for the lean assessment in SME: a case study," in Proceedings of the Winter Simulation Conference (WSC '11), pp. 2403-2413, Phoenix, Ariz, USA, December 2011.

[9] M. Taleghani, "Key factors for implementing the lean manufacturing system," Journal of American Science, vol. 6, no. 7, pp. 287291, 2010.

[10] M. Holweg, “The genealogy of lean production," Journal of Operations Management, vol. 25, no. 2, pp. 420-437, 2007.

[11] S. Vinodh and S. R. Balaji, "Fuzzy logic based leanness assessment and its decision support system," International Journal of Production Research, vol. 49, no. 13, pp. 4027-4041, 2011.

[12] D. Bailey, "Automotive news calls Toyota world no 1 car maker," 2008.

[13] S. Vinodh and K. C. Suresh, "Leanness assessment using multigrade fuzzy approach," International Journal of Production Research, vol. 49, no. 2, pp. 431-445, 2011.

[14] A. M. Deif, "Dynamic analysis of a lean cell under uncertainty," International Journal of Production Research, vol. 50, no. 4, pp. 1127-1139, 2012.

[15] B. Sezen, I. Karakadilar, and G. Buyukozkan, "Proposition of a model for measuring adherence to lean practices: applied to Turkish automotive part suppliers," International Journal of Production Research, vol. 50, no. 14, pp. 3878-3894, 2012.

[16] "Definition of technology," Merriam-Webster, 2007.

[17] J. S. Groff, "Dynamic systems modeling in educational system design \& policy," New Approaches in Educational Research, vol. 2, no. 2, pp. 72-81, 2013.

[18] A. Brose, A. Fügenschuh, P. Gausemeier, I. Vierhaus, and G. Seliger, "A system dynamic enhancement for the scenario technique," ZIB-Report 13-24, 2013.

[19] H. Feng, D. Yu, Y. Deng, M. P. Weinstein, and G. Martin, "System dynamic model approach for urban watershed sustainability study," International Journal of Sustainable Development, vol. 5, no. 6, pp. 69-80, 2012.

[20] J. D. Sterman, Business Dynamics: Systems Thinking and Modeling for a Complex World, McGraw-Hill, Irwin, Pa, USA, 2000.

[21] T. Daniel and L. Bengt, "Aggregate analysis of manufacturing systems using system dynamics and ANP," Computers and Industrial Engineering, vol. 49, no. 1, pp. 98-117, 2005.

[22] S. K. Somavarapu, System dynamics approach to understand the role of information technology in the evolution of next generation integrated product development systems, Massachusetts Institute of Technology, 2005.

[23] H. Shafiul, M. Al-Hussein, and P. Gillis, "Advanced simulation of tower crane operation utilizing system dynamics modeling and lean principles," in Proceedings of the Winter Simulation Conference (WSC '10), 2010.

[24] S. M. Dehghani, M. S. Owlia, B. Kiani, and K. Noughandarian, "Analysis of EFQM excellence model using system dynamics," Iranian Journal of Management Sciences, vol. 3, no. 12, pp. 65-82, 2009. 

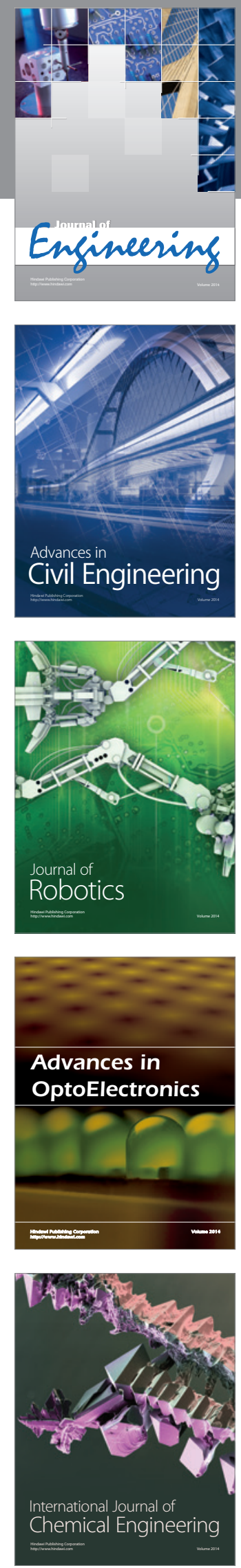

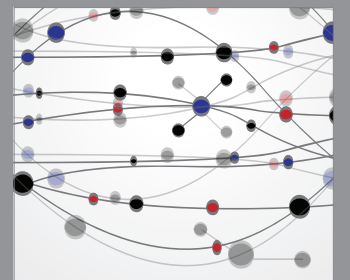

The Scientific World Journal
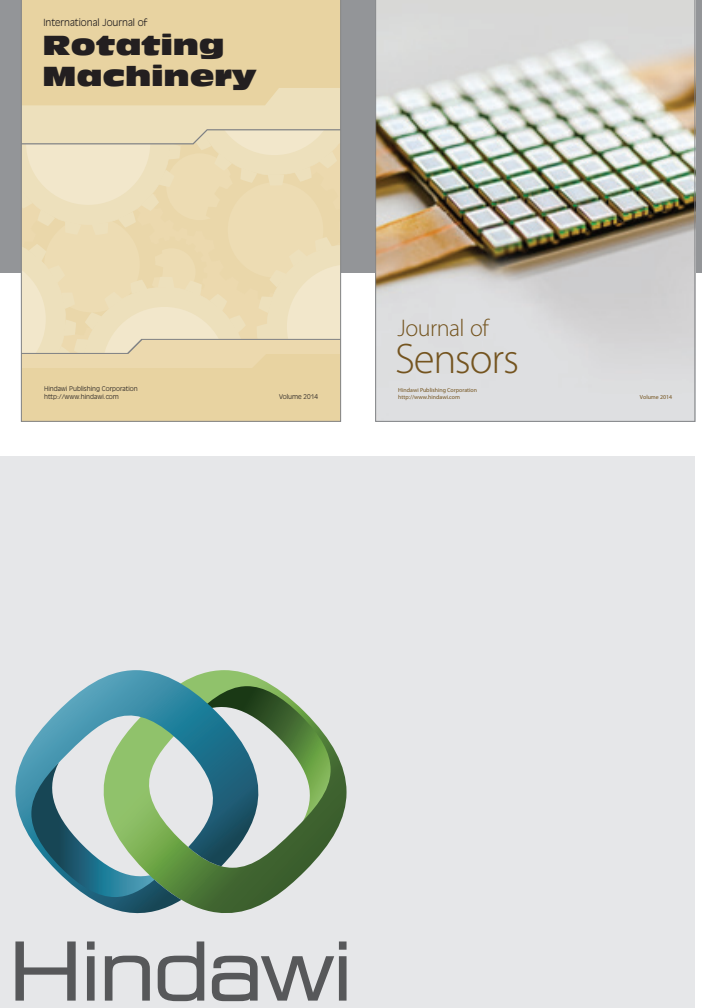

Submit your manuscripts at http://www.hindawi.com
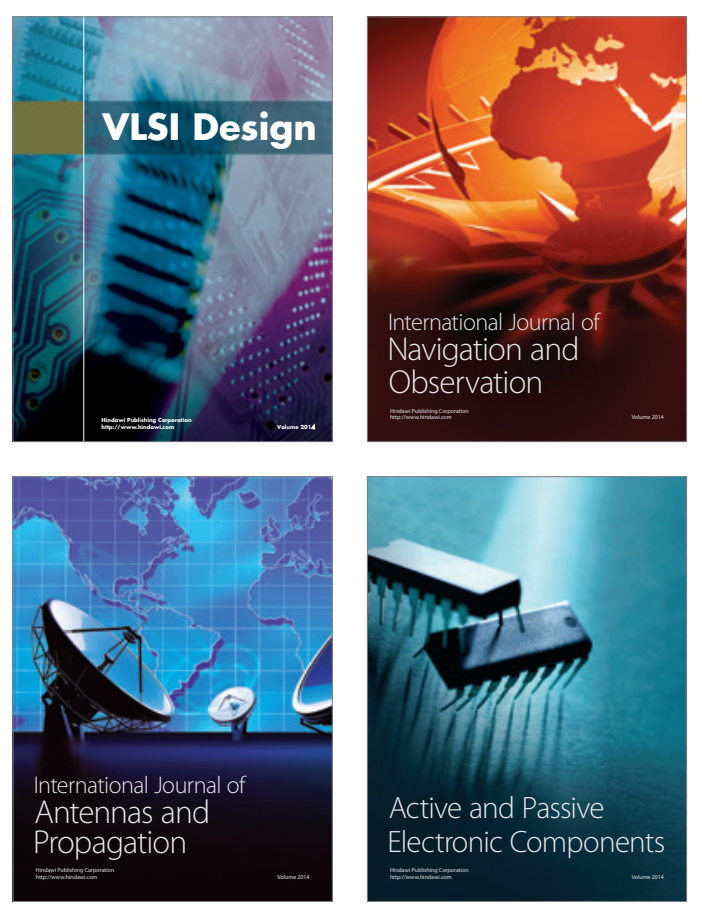
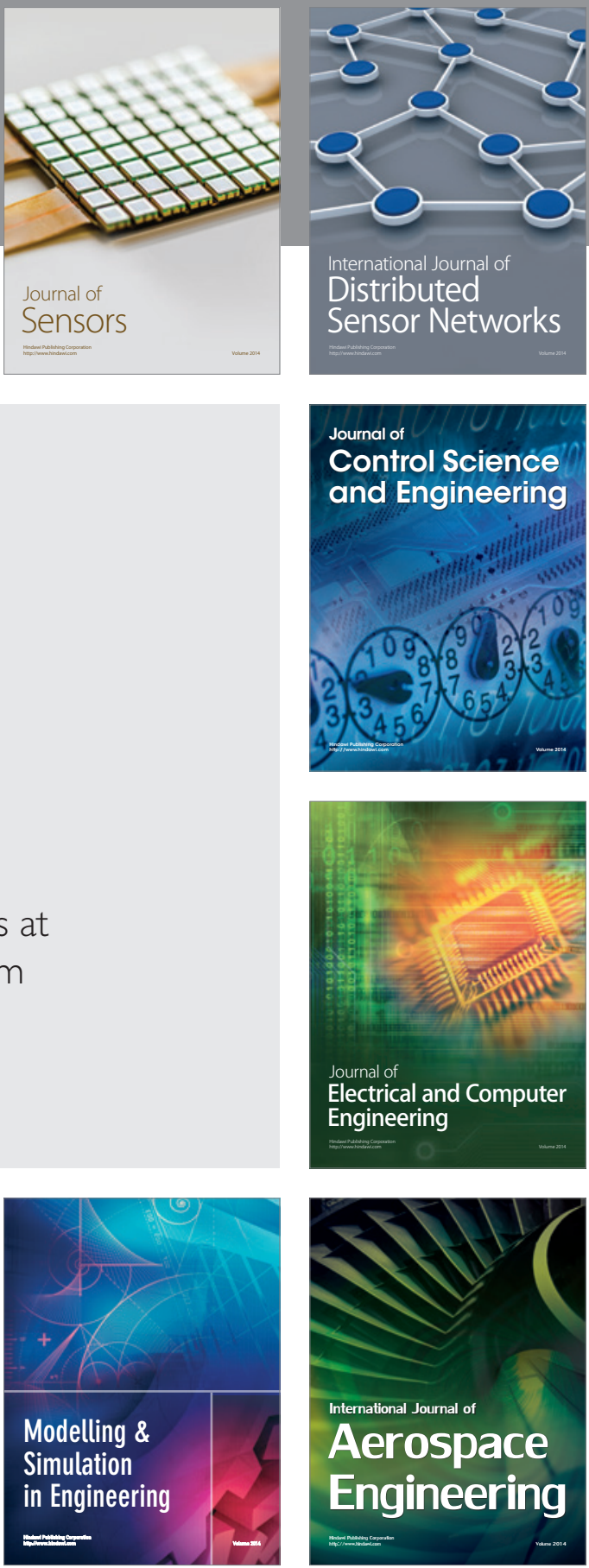

Journal of

Control Science

and Engineering
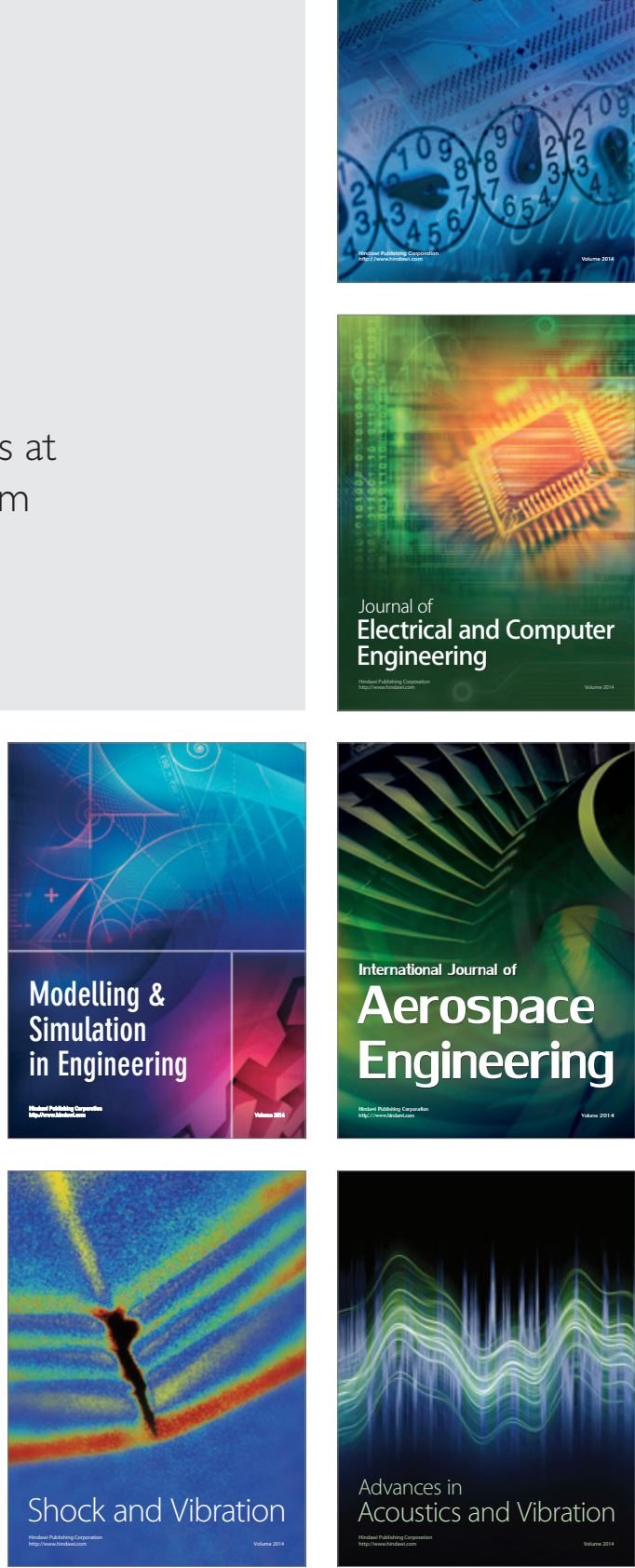